\title{
Non-synonymous MAPK Family Gene Mutation
}

National Cancer Institute

\section{Source}

National Cancer Institute. Non-synonymous MAPK Family Gene Mutation. NCI

Thesaurus. Code C136638.

A point mutation in a gene that is a member of the MAPK gene family that encodes an amino acid substitution in a MAPK family protein. 